\title{
Health-Promoting Lifestyle of Adolescents with $\beta$-Thalassemia Based on Precede Model in Ahvaz, Iran, 2016
}

\author{
Mahin Gheibizadeh, ${ }^{1,2}$ Malihe Bazpour,,2, Amal Saki Malehi, ${ }^{3,4}$ and Bijan Keikhaei ${ }^{4}$ \\ ${ }^{1}$ Nursing Care Research in Chronic Diseases, Ahvaz Jundishapur University of Medical Sciences, Ahvaz, IR Iran \\ ${ }^{2}$ Department of Nursing, School of Nursing and Midwifery, Ahvaz Jundishapur University of Medical Sciences, Ahvaz, IR Iran \\ ${ }^{3}$ Department of Biostatistics and Epidemiology, School of Public Health, Ahvaz Jundishapur University of Medical Sciences, Ahvaz, IR Iran \\ ${ }^{4}$ Health Research Institute, Thalassemia and Hemoglobinopathy Research Center, Ahvaz Jundishapur University of Medical Sciences, Ahvaz, IR Iran \\ "Corresponding author: Malihe Bazpour, Department of Nursing, School of Nursing and Midwifery, Ahvaz Jundishapur University of Medical Sciences, Ahvaz, IR Iran. Tel: \\ +98-9304923155, Fax: +98-6133738331, E-mail: m_bazpoor@yahoo.com
}

Received 2016 May 20; Revised 2016 June 30; Accepted 2016 July 04.

\begin{abstract}
Background: Lifestyle as a health promotion component contains six dimensions of stress management, health-responsibility, interpersonal relationships, spiritual growth, nutrition and physical activity. The current study aimed to determine the healthpromoting lifestyle of adolescents with $\beta$-thalassemia, based on Precede model to analyze behavior.

Methods: It was a descriptive cross-sectional study conducted in February 2016 on 64 adolescents with $\beta$-thalassemia and the age range of 16 - 20 years selected by census sampling method. Data were collected by two self-reporting questionnaires; healthpromoting lifestyle profile (HPLP) II and a researcher-made questionnaire based on Precede model. Data were analyzed using SPSS ver. 22 by applying descriptive statistics of absolute and relative frequency distribution, central tendency, mean and standard deviation, and analytical statistics of spearman correlation and Mann-Whitney U test.

Results: The mean age of participants was $17.98 \pm 1.36$ years and the mean overall score of lifestyle of adolescents under study was $106.23 \pm 8.54$. Based on the findings of the current study, the overall lifestyle of adolescents with $\beta$-thalassemia was correlated with their knowledge and attitude. In addition, the standardized mean score of knowledge was greater in females than males $(\mathrm{P}$ value $=$ 0.05).

Conclusions: Overall health-promoting lifestyle of the studied adolescents with $\beta$-thalassemia was unsatisfactory. Due to the impact of adopted lifestyle on the current and future health of adolescents, it is important that the necessary measures are taken to encourage more young people with $\beta$-thalassemia to adopt a healthy lifestyle.
\end{abstract}

Keywords: Lifestyle, Health-Promoting Lifestyle, $\beta$-Thalassemia, Precede Model, Adolescents

\section{Background}

Thalassemia, created due to a decrease or lack of hemoglobin chain synthesis, is the most common inherited blood disorder in the world (1). It is estimated that 70'000 children are born with various forms of thalassemia every year, and more than half of these births are affected by severe forms of $\beta$-thalassemia (2), with high prevalence in the Mediterranean region, East- and SouthEast Asia (3). Given that Iran is located in the middle of the thalassemia belt, it has a high rate of patients with thalassemia (4). The disease is a significant health complication in $71 \%$ of 229 countries worldwide including Iran (5).

Thalassemia, similar to any other chronic disease affects various aspects of a person's life (6) and people with the disease face serious problems in health that ultimately causes damage to the patient's health status (7).

Although in recent years several advanced methods are discovered to prevent this disease, many young people are still have this disease. In Iran, $85 \%$ of patients with tha- lassemia are adolescents (8). This increases the sensitivity to the health status of adolescents with thalassemia, since teenagers experience many physical, psychological, social and behavioral changes (9). Adolescence is the golden age to promote adulthood healthy status for the patients due to form a healthy lifestyle in this period. World health organization (WHO) also believes that the fight against unhealthy way of life at an early age has a significant impact on health in adulthood (10); therefore, factors affecting a healthy lifestyle should be identified at this time since the adolescence behaviors become a basis for the later stages of life in terms of health status (11). In fact, a healthy lifestyle is one of the major criteria that determine health (12).

Lifestyle is an individual's typical way of life and includes activities and attitudes that influence his/her health, which can be healthy or unhealthy. A healthy lifestyle may result in better health and happiness, and in contrast, an unhealthy lifestyle may cause illness and morbidity (13). The health promoting lifestyle is a combi- 
nation of six dimensions of stress management, responsibility against health, interpersonal relationships, spiritual growth, nutrition and physical activity (14). The number of healthy behaviors adopted by people is associated with mortality rate, as it reduces the mortality rate by $66 \%$ (15).

Lifestyle is introduced as a key issue in the context of health promotion and is closely related to the quality of life $(16,17)$, and several studies confirmed this relation (1822 ). In the literature review, no studies were found on identifying all aspects of lifestyle among adolescents with thalassemia in Iran; however, according to other studies conducted in the field of quality of life, the quality of life in patients with thalassemia was reported undesirable particularly in adolescence (23-29). Findings of previous studies $(12,30,31)$ suggested low nutrition performance and poor physical activity among adolescents, which were due to their low knowledge and poor attitudes towards healthy lifestyles. Hence, the need to examine the lifestyle in patients with thalassemia seems necessary due to low quality of life in such patients.

Effective health promotion needs advanced analysis of issues related to health, and theories and models are essential tools to accomplish this importance. The Precede model is one of the typical models in health promotion. This model considers the various factors that shape the health status and interpret these factors. The Precede model is an acronym for predisposing, reinforcing and enabling constructs in educational diagnosis and evaluation. In fact, during the fourth stage of the model (educational diagnosis and evaluation), many factors which could potentially influence behavior are identified and given in three categories including predisposing, reinforcing and enabling factors. Predisposing factors precede behavioral change and provide motivation for behaviors such as knowledge, beliefs, attitudes, values and perceptions. Enabling factors are considered preliminary to behavioral or environmental changes and allow the realization of a motivation, such as access to resources, availability, rules, regulations and skills. Reinforcing factors are the factors that make behavior persistent and permanent and encourage keeping the behavior, such as family, peers, teachers and leaders (32). Therefore, Precede model is a useful framework to better identify lifestyle factors that affect adolescents with $\beta$-thalassemia. In fact, gaining information regarding a very little discussed area of healthpromoting lifestyle adaptation among adolescents with $\beta$ thalassemia by applying a theoretical framework research can lead to principal and rich data.

Given the importance of studying and understanding the lifestyle of adolescents with $\beta$-thalassemia and the valuable role of Precede to facilitate the process of pattern recognition of adolescents' lifestyle, the current pa- per aimed to determine the factors associated with lifestyle of adolescents with $\beta$-thalassemia in Ahvaz based on Precede model behavioral analysis phase.

\section{Methods}

It was a descriptive cross-sectional study conducted in February 2016. Sample of the study consisted of 64 adolescents with the age range of 16 - 20 years who referred to Ahvaz thalassemia center. According to the study inclusion criteria, age from 16 to 20 years, having thalassemia major, having records in Ahvaz center of thalassemia and the ability to complete the questionnaire, the total population was 64 adolescents who were all invited to participate in the study. In other words, a census sampling method was adopted for the study. The response rate was $100 \%$.

\subsection{Data Collection Tools}

The applied tools in the study were two self-reporting questionnaires as follows:

\subsubsection{The Health-Promoting Lifestyle Profile II}

The health-promoting lifestyle profile (HPLP II) was designed by Walker et al. in 1978. In the current study, the Persian version of HPLP II was used (33). This multidimensional tool assesses health promoting behaviors in six aspects of nutrition (seven items), physical activity (seven items), responsibility for health (thirteen items), stress management (six items), interpersonal relationship (eight items), and self-actualization (eleven items). The questionnaire included 52 questions based on a four-item Likert scale; 1) never, 2) sometimes, 3) often and 4) always. The total score of health promoting behaviors is between 52 and 208 with higher scores indicating a healthier lifestyle. For each aspect of behaviors, a separate score was calculated; therefore, the score of each sub-scale were calculated by the scores of the answers given to the questions of the same subscale. In each subscale and in total scale, achieving less than or equal to $49 \%$ of the score indicates poor status, $50 \%$ to $74 \%$ of the total score represents an average status, and greater than $75 \%$ indicates a good status.

\subsubsection{Researcher-Made Questionnaire Based on PRECEDE Model}

To make and codify this questionnaire, after studying literature and references, the questions were designed to determine Predisposing, Enabling and health behavior Reinforcing factors. The questionnaire had four sections as demographic information (including age, gender, education of the subject and his/her parents, and the occupation of his/her parents); predisposing factors (including ten questions regarding knowledge and fifteen questions 
regarding attitudes toward healthy lifestyle); enabling factors (includes four questions to measure skills of stress management, interpersonal relations, self-actualization, access to and the use of training references); and reinforcement factors (consists of three questions to measure support and encouragement of peers, family and healthcare staff). Questions pertaining to knowledge, enabling factors, and reinforcement factors were scored in the form of yes $=1$, no $=0$; while the attitude questions were scored based on a 4-item Likert scale ranged from strongly disagree $=1$ to strongly agree $=4$. Therefore, the total score range to predispose factors section was 25 - 70; enabling factors section 0-4; and reinforcement factors section 0 3 , with higher scores indicating a better status to move toward the healthy lifestyle.

\subsection{Validity and Reliability of the Study Tools}

To determine the content validity of the researchermade questionnaire, 10 faculty members evaluated the questionnaire and their comments were applied to the questionnaire. For the researcher-made questionnaire, content validity rate (CVR) was 0.92 and CVI was 0.96 . For reliability of the questionnaire, a test-retest method with two weeks interval was conducted for a sample of 15 individuals and Pearson correlation coefficient for all questions was 0.92. The correlation coefficients for knowledge, attitude, enabling factors and reinforcing factors were $0.89,0.92,0.90$ and 0.89 , respectively.

The reliability of original version of health-promoting lifestyle profile introduced by Walker et al. using Cronbach's alpha for self-actualization, health responsibility, physical activity, interpersonal relations, stress management and nutrition were $0.86,0.86,0.85,0.87,0.79$ and 0.80 , respectively. In other words, a 0.94 Cronbach's alpha was determined for the entire questionnaire (34).

Validity and reliability of the Persian version of the health-promoting lifestyle profile was obtained by Zeidi et al. They reported Cronbach's alpha of 0.64, 0.86, 0.75, 0.91, $0.79,0.81$, and 0.82 for self-actualization, health responsibility, interpersonal relations, stress management, physical activity, nutrition and the whole questionnaire, respectively (35).

\subsection{Data Analysis}

Data were analyzed by SPSS ver. 22 . To describe the demographic profile and the status of health promoting lifestyle, descriptive statistics such as absolute and relative frequency distribution as well as central tendency and dispersion such as mean and standard deviation were used. As the distribution of data after conducting KolmogorovSmirnov test was abnormal, to determine the correlation between lifestyle and the model constructs a nonparametric test of spearman correlation was used. Mann-Whitney U test was another nonparametric test used to compare the two groups of males and females.

\subsection{Ethical Considerations}

The ethics committee of Ahvaz Jundishapur University of Medical Sciences (IR.AJUMS.REC.1394.507) approved the study. In the study, the researchers were trained on ethical issues such as respect for the right to participate voluntarily, obtaining consent from to participate in the project and informing the participants of the purpose of the study.

\section{Results}

In the study, 64 adolescents with $\beta$-thalassemia and the age range of 16 - 20 years in Ahvaz were studied in terms of lifestyle and its relationship with behavior based on Precede model. The mean age of the participants was $17.98 \pm$ 1.36 years. The frequency and percentage of other demographic characteristics of adolescents under study is presented in Table 1 . The mean and standard deviation of six dimensions of lifestyle are presented in Table 2. Based on the study findings, the overall score mean of adolescents' lifestyle was $106.23 \pm 8.54$. The overall lifestyle of adolescents with $\beta$-thalassemia showed a significant correlation with their knowledge and attitude (Table 3). In addition, the standardized mean score of knowledge was greater in females than males; therefore a statistically significant difference was observed between the two genders ( $\mathrm{P}$ value $=$ 0.05).

\section{Discussion}

The current study findings showed that adoption to health promoting behaviors in adolescents with $\beta$ thalassemia was intermediate. In addition, males had more compliance with the health-promoting lifestyle than females. Although there was no study that discussed lifestyle in adolescents with thalassemia, the results of similar studies of lifestyles in healthy young females (36) and males (37) showed that lifestyle among males and females in terms of health promoting behaviors was in an intermediate level. In addition, the results of the study by Tavafian in Bandar Abbas showed that lifestyle level in healthy adolescents was undesirable (38). This evidence implies that young people generally do not follow a healthy lifestyle and there is a need for measures to develop healthy lifestyles among adolescents in general and young adults with thalassemia specifically. 
Table 1. Participants Demographic Characteristics $(n=64)$

\begin{tabular}{|c|c|}
\hline Characteristics & No. (\%) \\
\hline \multicolumn{2}{|l|}{ Gender } \\
\hline Female & $33(51.5)$ \\
\hline Male & $31(48.5)$ \\
\hline \multicolumn{2}{|l|}{ Thalassemia patient(s) in the family } \\
\hline Yes & $43(67.2)$ \\
\hline No & $21(32.8)$ \\
\hline \multicolumn{2}{|l|}{ Father's education level } \\
\hline Uneducated & $4(6.3)$ \\
\hline Under high school diploma & $33(51.6)$ \\
\hline Diploma & $21(32.8)$ \\
\hline Master & $6(9.4)$ \\
\hline \multicolumn{2}{|l|}{ Mather's education level } \\
\hline Uneducated & $16(25)$ \\
\hline Under hid school diploma & $15(23.4)$ \\
\hline Diploma & $33(51.6)$ \\
\hline Master & 0 \\
\hline \multicolumn{2}{|l|}{ Father's occupation } \\
\hline Employee & $16(25)$ \\
\hline Worker & $9(14.1)$ \\
\hline Pensioner & $15(23.4)$ \\
\hline Self-employed & $24(37.5)$ \\
\hline \multicolumn{2}{|l|}{ Mather's occupation } \\
\hline Housewife & $59(92.1)$ \\
\hline Employed & $5(8.9)$ \\
\hline \multicolumn{2}{|l|}{ Adolescent's education level } \\
\hline Under high school diploma & $43(67.2)$ \\
\hline Diploma & $21(32.8)$ \\
\hline
\end{tabular}

In the current study, the most undesirable behavioral score was associated with physical activity. In this regard, studies conducted by Wang et al. and Tol et al. also reported the poor level of physical activity among adolescents (39, 40). These results were in line with those of the current study. In fact, results of the current study and other studies indicated that generally, both healthy and diseased teens were not enjoying a good level of physical activity.

In the present study, adolescents achieved highest scores in responsibility against health, which was different from the results of similar studies conducted on healthy adolescents in Turkey (41), Hong Kong (42), and Isfahan, Iran (40). In these studies, the self-actualization achieved the highest score while the responsibility against health
Table 2. The Mean and Standard Deviation of Lifestyle Dimensions and Behavior Analysis Based on Precede Model

\begin{tabular}{|lc|}
\hline Dimensions & Mean \pm Standard Deviation \\
\hline Health-responsibility & $26.48 \pm 3.63$ \\
\hline Spiritual growth & $24.95 \pm 3.73$ \\
\hline Interpersonal relations & $17.18 \pm 2.30$ \\
\hline Stress management & $12.15 \pm 1.89$ \\
\hline Physical activity & $11.75 \pm 2.34$ \\
\hline Nutrition & $15.45 \pm 2.13$ \\
\hline Predisposing factors & \\
\hline \multicolumn{1}{c}{ knowledge } & $5.18 \pm 1.06$ \\
\hline \multicolumn{1}{c}{ attitude } & $36.92 \pm 3.78$ \\
\hline Enabling factors & $0.85 \pm 0.75$ \\
\hline Reinforcing factors & $2.09 \pm 0.68$ \\
\hline
\end{tabular}

Table 3. The Correlation Between Lifestyle and behavior Analysis Based on Precede Model

\begin{tabular}{|c|c|c|}
\hline \multirow[t]{2}{*}{ Variables } & \multicolumn{2}{|l|}{ Lifestyles } \\
\hline & Spearman Correlation & P Value \\
\hline \multicolumn{3}{|l|}{ Predisposing factors } \\
\hline Knowledge & 0.471 & 0.0001 \\
\hline Attitude & 0.309 & 0.007 \\
\hline Enabling factors & 0.239 & 0.029 \\
\hline Reinforcing factors & 0.118 & 0.176 \\
\hline
\end{tabular}

had gained lower rates among the six areas. Actually, chronic diseases require hard work to treat, and patients with thalassemia, due to the nature of their disease, are involved in many issues at all stages of their lives, which make them more sensitive regarding their own health. Therefore, these differences in the findings are not eccentric.

Based on Precede model, factors affecting a health problem during educational phase of this model are classified in three categories: predisposing, enabling, and reinforcing. In the current study, knowledge and attitude factors were considered as predisposing factors. The study findings showed a direct relationship between the lifestyle of adolescents with $\beta$-thalassemia and their knowledge. In other words, increasing the knowledge of adolescents improves their lifestyle. In addition, a direct relationship was observed between adolescents' lifestyle and their attitudes, and the adolescents who had a positive attitude towards healthy lifestyle had a better lifestyle, which was in line with similar studies which employed educational 
diagnosis of Precede model to study a health problem (43). Similar to other adolescents, the adolescents with thalassemia lacked information. The results of studies by Hamayeli Mehrabani et al. (30) and Yabandeh et al. (31) on healthy adolescents, and Mehdikhani et al. on adolescent with thalassemia (44) also confirmed lack of information in their studied populations. Knowledge has a positive effect on health care and on increasing health behaviors. To make continuous changes in behavior, creating knowledge and positive attitude is useful and logical (45); therefore adolescents should be trained and supported for healthy behaviors such as healthy lifestyle. The study conducted by Safari et al. showed the impact of knowledge, attitude and training on lifestyle of male and female adolescents (46). Due to the direct connection between knowledge and attitude with adopting a healthy lifestyle, on the other adolescents' lack of knowledge in the field of healthy lifestyle, it is necessary to provide continuous and comprehensive training programs in this regard.

The results of the study showed a direct relationship between the lifestyle of adolescents with $\beta$-thalassemia and enabling factors (such as access to educational resources and educational resources used). Findings of different studies indicate a significant relationship between enabling factors and health behaviors (43). In the current study, no significant association was observed between lifestyle and reinforcing factors while Moshki et al. showed the effectiveness of this factor on the quality of life (43).

The findings of the study provided valuable information on the compliance status of healthy lifestyle in adolescents with thalassemia, their knowledge and attitudes about healthy lifestyles and enabling and reinforcing factors which was in some aspects similar to that of healthy adolescents and differed in some aspects. Therefore, there was a need for more comparative studies between ill and healthy adolescents for in depth explanation of similarities and differences.

\subsection{Conclusion}

The results of the study showed that overall, healthpromoting lifestyle of adolescents was not satisfactory, and in the meantime, regular physical activity had the lowest score, which indicated that a sedentary lifestyle was a common and a serious problem among adolescents. Furthermore, considering the low score of knowledge and attitude of adolescents with $\beta$-thalassemia, health care authorities should plan effective educational programs to improve the knowledge and attitude of adolescents with $\beta$ thalassemia in the field of health promoting lifestyle. It is recommended to conduct studies with larger sample sizes also analytical researches on this issue in the future to find the exact cause of low levels of health-promoting lifestyle in adolescents; therefore their lifestyle can improve based on the obtained results. In addition, studying and designing educational interventions using other health educational models and theories in the field of health promotion for adolescents with chronic diseases are recommended.

\subsection{Limitations and Strengths}

This descriptive cross-sectional study provided valuable basic information in a limited studied area of healthpromoting lifestyle adaptation among adolescents with $\beta$-thalassemia and factors affecting it using the Precede model. This basic information can play an important role in planning health-promoting services for adolescents with $\beta$-thalassemia. On the other hand the study information can work as a basis to design experimental interventions in this field.

One important limitation of the study was the relatively low sample size resulting from small size of the whole population of interest that was out of the researchers' control. Due to this limitation, the entire population was invited to participate in the study. As data collection in this study was conducted by self-reporting tools, there is the probability of report and recall biases on behalf of the participants, which was out of control.

\section{Acknowledgments}

The authors hereby express their appreciation to the sponsor of the project as well as personnel of Shafa thalassemia clinic and all adolescents participating in the project.

\section{Footnotes}

Authors' Contribution: Mahin Gheibizadeh, Malihe Bazpour, Amal Saki Malehi, and Bijan Keikhaei were responsible for the study conception and design, performing data analysis, and drafting the manuscript. Amal Saki Malehi was responsible for the statistical analysis. Data collection conducted by Malihe Bazpour. All the authors approved the final manuscript.

Funding/Support: This article is part of the MSc thesis of the second author (Malihe Bazpour), which was financially supported by Nursing Care Research in Chronic Diseases of Ahvaz Jundishapur University of Medical Sciences (grant No: CDCRC-9407). 


\section{References}

1. Mashhadi MA, Sepehri Z, Heidari Z, Shirzaee E, Kiani Z. The prevalence of zinc deficiency in patients with thalassemia in South East of iran, sistan and baluchistan province. Iran Red Crescent Med J. 2014;16(8):ee6243. doi: 10.5812/ircmj.6243. [PubMed: 25389495].

2. Mettananda S, Gibbons RJ, Higgs DR. alpha-Globin as a molecular target in the treatment of beta-thalassemia. Blood. 2015;125(24):3694701. doi: 10.1182/blood-2015-03-633594. [PubMed: 25869286].

3. Surapolchai P, Satayasai W, Sinlapamongkolkul P, Udomsubpayakul U. Biopsychosocial predictors of health-related quality of life in children with thalassemia in Thammasat University Hospital.J Med Assoc Thai. 2010;93 Suppl 7:S65-75. [PubMed: 21298837].

4. Abolghasemi H, Amid A, Zeinali S, Radfar MH, Eshghi P, Rahiminejad MS, et al. Thalassemia in Iran: epidemiology, prevention, and management. J Pediatr Hematol Oncol. 2007;29(4):233-8. doi: 10.1097/MPH.ob013e3180437e02. [PubMed: 17414565].

5. Ramezanzadeh M, Salehi M, Salehi R. Assessment of high resolution melt analysis feasibility for evaluation of beta-globin gene mutations as a reproducible, cost-efficient and fast alternative to the present conventional method. Adv Biomed Res. 2016;5:71. doi: 10.4103/22779175.180640. [PubMed: 27169102].

6. Triantafyllou AI, Vyssoulis GP, Karpanou EA, Karkalousos PL, Triantafyllou EA, Aessopos A, et al. Impact of beta-thalassemia trait carrier state on cardiovascular risk factors and metabolic profile in patients with newly diagnosed hypertension. J Hum Hypertens. 2014;28(5):328-32. doi: 10.1038/jhh.2013.102. [PubMed: 24152820].

7. Wong LH, Chan FW, Wong FY, Wong EL, Huen KF, Yeoh EK, et al. Transition care for adolescents and families with chronic illnesses. J Adolesc Health. 2010;47(6):540-6. doi: 10.1016/j.jadohealth.2010.04.002. [PubMed: 21094430].

8. Razzazan N, Ravanipour M, Gharibi T, Motamed N, Zarei A. Effect of self-management empowering model on the quality of life in adolescents and youths with major thalassemia. J Nurs Educ. 2014;3(2):48-59.

9. Klein JD, Wilson KM. Delivering quality care: adolescents' discussion of health risks with their providers.JAdolesc Health. 2002;30(3):190-5. [PubMed: 11869926].

10. Dupuy M, Godeau E, Vignes C, Ahluwalia N. Socio-demographic and lifestyle factors associated with overweight in a representative sample of 11-15 year olds in France: results from the WHO-Collaborative Health Behaviour in School-aged Children (HBSC) cross-sectional study. BMC Public Health. 2011;11:442. doi: 10.1186/1471-2458-11-442. [PubMed: 21649892].

11. Bibiloni Mdel M, Pich J, Cordova A, Pons A, Tur JA. Association between sedentary behaviour and socioeconomic factors, diet and lifestyle among the Balearic Islands adolescents. BMC Public Health. 2012;12:718. doi: 10.1186/1471-2458-12-718. [PubMed: 22935441].

12. Cheng J, Wang T, Li F, Xiao Y, Bi J, Chen J, et al. Self-rated health status and subjective health complaints associated with health-promoting lifestyles among urban Chinese women: a cross-sectional study. PLoS One. 2015;10(2):e0117940. doi:10.1371/journal.pone.0117940. [PubMed: 25671578].

13. Mehri A, Solhi M, Garmaroudi G, Nadrian H, Sighaldeh SS. Health Promoting Lifestyle and its Determinants Among University Students in Sabzevar, Iran. Int J Prev Med. 2016;7:65. doi: 10.4103/2008-7802.180411. [PubMed: 27141284].

14. Malakouti J, Sehhati F, Mirghafourvand M, Nahangi R. Relationship between Health Promoting Lifestyle and Perceived Stress in Pregnant Women with Preeclampsia. J Caring Sci. 2015;4(2):155-63. doi: 10.15171/jcs.2015.016. [PubMed: 26161369].

15. Loef $M$, Walach $H$. The combined effects of healthy lifestyle behaviors on all cause mortality: a systematic review and meta-analysis. Prev Med. 2012;55(3):163-70. doi: 10.1016/j.ypmed.2012.06.017. [PubMed: $22735042]$.
16. Kurt AS. The Relationship between Healthy Lifestyle Behaviors and Health Locus of Control among Nursing and Midwifery Students. Am J Nurs Res. 2015;3(2):36-40.

17. Wang $\mathrm{D}$, Xing $\mathrm{XH}, \mathrm{Wu} \mathrm{XB}$. Healthy lifestyles of university students in China and influential factors. ScientificWorldJournal. 2013;2013:412950. doi: 10.1155/2013/412950. [PubMed: 23935418].

18. Thomson RL, Buckley JD, Lim SS, Noakes M, Clifton PM, Norman RJ, et al. Lifestyle management improves quality of life and depression in overweight and obese women with polycystic ovary syndrome. Fertil Steril. 2010;94(5):1812-6. doi: 10.1016/j.fertnstert.2009.11.001. [PubMed: 20004371].

19. Bourke L, Gilbert S, Hooper R, Steed LA, Joshi M, Catto JW, et al Lifestyle changes for improving disease-specific quality of life in sedentary men on long-term androgen-deprivation therapy for advanced prostate cancer: a randomised controlled trial. Eur Urol. 2014;65(5):865-72. doi: 10.1016/j.eururo.2013.09.040. [PubMed: 24119318].

20. Clark F, Jackson J, Carlson M, Chou CP, Cherry BJ, Jordan-Marsh $\mathrm{M}$, et al. Effectiveness of a lifestyle intervention in promoting the well-being of independently living older people: results of the Well Elderly 2 Randomised Controlled Trial. J Epidemiol Community Health. 2012;66(9):782-90. doi: 10.1136/jech.2009.099754. [PubMed 21636614].

21. Florez H, Pan Q, Ackermann RT, Marrero DG, Barrett-Connor E, Delahanty L, et al. Impact of lifestyle intervention and metformin on health-related quality of life: the diabetes prevention program randomized trial. J Gen Intern Med. 2012;27(12):1594-601. doi: 10.1007/s11606-012-2122-5. [PubMed: 22692637].

22. Mishra SI, Scherer RW, Geigle PM, Berlanstein DR, Topaloglu O, Gotay CC, et al. Exercise interventions on health-related quality of life for cancer survivors. Cochrane Database Syst Rev. 2012(8):CD007566. doi: 10.1002/14651858.CD007566.pub2. [PubMed: 22895961].

23. Haghpanah S, Nasirabadi S, Ghaffarpasand F, Karami R, Mahmoodi M, Parand S, et al. Quality of life among Iranian patients with betathalassemia major using the SF-36 questionnaire. Sao Paulo Med J. 2013;131(3):166-72. [PubMed: 23903265].

24. Clarke SA, Skinner R, Guest J, Darbyshire P, Cooper J, Shah F, et al. Health-related quality of life and financial impact of caring for a child with Thalassaemia Major in the UK. Child Care Health Dev. 2010;36(1):118-22. doi: 10.1111/j.1365-2214.2009.01043.x. [PubMed: 19961496].

25. Kaheni S, Yaghobian M, Sharefzadah GH, Vahidi A, Ghorbani H, Abderahemi A. Quality of life in children with beta-thalassemia major at center for special diseases. Iran J Ped Hematol Oncol. 2013;3(3):108-13. [PubMed: 24575281].

26. Safizadeh H, Farahmandinia Z, Nejad SS, Pourdamghan N, Araste M. Quality of life in patients with thalassemia major and intermedia in kerman-iran (I.R.). Mediterr J Hematol Infect Dis. 2012;4(1):ee2012058. doi: 10.4084/MJHID.2012.058. [PubMed: 23170187].

27. Musallam KM, Khoury B, Abi-Habib R, Bazzi L, Succar J, Halawi R, et al Health-related quality of life in adults with transfusion-independent thalassaemia intermedia compared to regularly transfused thalassaemia major: new insights. Eur J Haematol. 2011;87(1):73-9. doi: 10.1111/j.1600-0609.2011.01623.x. [PubMed: 21480999].

28. Ajij M, Pemde HK, Chandra J. Quality of Life of Adolescents With Transfusion-dependent Thalassemia and Their Siblings: A Crosssectional Study. J Pediatr Hematol Oncol. 2015;37(3):200-3. doi: 10.1097/MPH.0000000000000244. [PubMed: 25171456].

29. Salama H, Hussein H, Al Faisal W, Belhool K, El Sawaf E, Wasfy A Health-Related Quality of Life in Transfusion-Dependent Thalassemia Major Patients and Associated Factors in Dubai, UAE, 2011. ME-JPA. 2014;5(3):3-10.

30. Hamayeli Mehrabani H, Mirmiranl P, Alaiin F, Azizi F. Changes in nutritional knowledge, attitude, and practices of adolescents in district 13 of Tehran after 4 years of education. Iran J Endocrinol Metabol. 2009;11(3):235-43. 
31. Yabandeh AP, Nejatizadeh AA, Mehrabani H, Dabiri F, Kamjoo A, Shahi A, et al. Assessment of nutritional status, dietary habits and physical activity of adolescents in Bandar Abbas, Iran. Bimonth J Hormozgan Univ Med Sci. 2014;17(6):455-63.

32. Crosby R, Noar SM. What is a planning model? An introduction to PRECEDE-PROCEED. J Public Health Dent. 2011;71 Suppl 1:S7-15. [PubMed: 21656942].

33. Walker SN, Sechrist KR, Pender NJ. The Health-Promoting Lifestyle Profile: development and psychometric characteristics. Nurs Res. 1987;36(2):76-81. [PubMed: 3644262].

34. Walker SN, Hill-Polerecky DM. Psychometric evaluation of the healthpromoting lifestyle profile II. ; 1996.

35. Zeidi I, Hajiagha A, Zeidi B. Reliability and validity of Persian version of the health-promoting lifestyle profile. JMUMS. 2012;22:S103.

36. Golmakani N, Naghibi F, Moharari F, Esmaily H. Health Promoting Life Style and Its Related Factors in Female Adolescents. J Midwifery Reprod Health. 2013;1(1):42-9.

37. Charandabi SM, Mirghafourvand M, Tavananezhad N, Karkhaneh M. Health promoting lifestyles and self-efficacy in male adolescents in Sanandaj, 2013. J Mazandaran Univ Med Sci. 2014;23(109):152-62.

38. Tavafian S, Aghamolaei T. Assessing lifestyle of high school students in Bandar Abbas, Iran. SJSPH. 2013;11(3):83-93.

39. Wang D, Ou CQ, Chen MY, Duan N. Health-promoting lifestyles of university students in mainland China. BMC Public Health. 2009;9:379. doi: 10.1186/1471-2458-9-379. [PubMed: 19814831].

40. Tol A, Tavassoli E, Shariferad GR, Shojaeezadeh D. Health-promoting lifestyle and quality of life among undergraduate students at school of health, Isfahan university of medical sciences. JEduc Health Promot. 2013;2:11. doi: 10.4103/2277-9531.108006. [PubMed: 24083261].

41. Can G, Ozdilli K, Erol O, Unsar S, Tulek Z, Savaser S, et al. Comparison of the health-promoting lifestyles of nursing and non-nursing students in Istanbul, Turkey. Nurs Health Sci. 2008;10(4):273-80. doi: 10.1111/j.1442-2018.2008.00405.x. [PubMed: 19128303].

42. Lee RL, Loke AJ. Health-promoting behaviors and psychosocial wellbeing of university students in Hong Kong. Public Health Nurs. 2005;22(3):209-20. doi: 10.1111/j.0737-1209.2005.220304.x. [PubMed: 15982194].

43. Moshki M, Mohammadzadeh F, Yaghubi R, Pariafsai F. Application of Behavioral Analysis Phase of PRECEDE Model on Women's Psychological Well-being in the Menopausal Period. J Neyshabur Univ Med Sci. 2015;3(2):39-51.

44. MehdiKhani B, Eslami A, Qorbani M, Azarkeivan A, Mohammadi Z, Khashayar P, et al. Knowledge, attitude, and preventive practice of major thalassemia patients regarding the importance of calcium and Vitamin D. J Appl Hematol. 2015;6(1):13.

45. Palank CL. Determinants of health-promotive behavior. A review of current research. Nurs Clin North Am. 1991;26(4):815-32. [PubMed: 1945937].

46. Safari M, Amini N, Eftekhar A, Mahmoudi M, Sanaeinasab H. Evaluation of an educational intervention based on PRECEDE PROCEED model toward lifestyle improvement among adolescents. Daneshvar Med. 2012;19(98):1-10. 